\title{
Canadian Adolescents' Internalized Symptoms in Pandemic Times: Association with Sociodemographic Characteristics, Confinement Habits, and Support
}

\author{
Kristel Tardif-Grenier ${ }^{1}$ (D) Isabelle Archambault ${ }^{2} \cdot$ Véronique Dupéré $^{2}$. \\ Amy K. Marks ${ }^{3}$. Elizabeth Olivier ${ }^{4}$
}

Accepted: 8 February 2021 / Published online: 25 March 2021

(c) The Author(s), under exclusive licence to Springer Science+Business Media, LLC part of Springer Nature 2021

\begin{abstract}
Adolescence is a time of increased risk for developing symptoms of anxiety and depression, especially for girls. The stress and social isolation experienced during confinement add new threats to already vulnerable adolescents' daily lives. This study is aimed at determining which sociodemographic characteristics (age, family composition, achievement), confinement habits (schedule, new hobby, sleep duration, cellphone and computer use, sports, schoolwork), and sources of support (parents and teachers) are associated with more or less internalized symptoms in Canadian adolescents. Differences between boys and girls are also investigated. Between April 8 and 30 (2020) and through an online survey, 895 Canadian adolescents (74\% girls) aged between 12 and 17 years $(M=14.7)$ were recruited. Path analysis was performed to identify significant associations between sociodemographic characteristics, confinement habits, support variables, and internalized symptoms. Independent samples t-tests and invariance tests were conducted to compare boys and girls. Results suggest that certain confinement habits (time spent using cellphones, doing sports and schoolwork, finding a new hobby) and support variables (parents working outside the home) were significantly and negatively associated with internalized symptoms. Regarding the sex differences, girls used their cellphones more and invariance test results showed that all associations between predictors and symptoms were statistically similar for boys and girls. This study's results help understand better adolescents' experience in confinement. It sheds light on the habits likely to characterize those who are less at risk of experiencing distress, making it possible to better support adolescents during this challenging period.
\end{abstract}

Keywords Adolescents · COVID-19 · Confinement · Anxiety · Depression

Kristel Tardif-Grenier

kristel.tardif-grenier@uqo.ca

Extended author information available on the last page of the article 


\section{Adolescents: a Population Strongly Affected by the Lockdown}

Like everywhere in the world, the COVID-19 pandemic is affecting Canada, resulting in drastic confinement measures and a complete change in the psychosocial environment. Suddenly on March 15 and for an indefinite period of time, teenagers in Quebec (Canada) had their studies interrupted, were isolated from their friends, and deprived of their leisure and sports activities, just like $90 \%$ of children and teenagers in the world [1]. The confinement may have represented an opportunity for some adolescents to benefit from family time, but the disadvantages may outweigh these benefits.

Although adolescents seem to be physically less affected with COVID-19 as compared to adults, the psychological impacts they suffer are potentially more severe than those observed in the adult population for several reasons [2, 3]. First, adolescents are generally more at risk of experiencing anxiety and depressive symptoms, mainly due to the onset of puberty and the hormones, especially in girls $[4,5]$. Second, the lockdown resulted in the deprivation of adolescent socialization contexts, school closure, and limited access to their friends at an age where peer interaction is a central aspect of development [6]. Adolescence is also characterized by identity exploration, increased autonomy from parents, and the initiation of romantic relationships [7]. Although the family still represents an essential developmental context for teenagers, detachment from parents represents a significant milestone for adolescents who are biologically and psychologically driven to be with peers [8]. Nevertheless, it is undoubtedly social isolation, a risk factor for many mental disorders, that mostly affected young people during the lockdown, mainly because they found themselves in a stressful situation and could not benefit from their friends' social support [9, 10]. On top of that, school closure that was associated with a lack of activity and structure, problematic dietary and sleeping habits, and disappointment in some teenagers who saw their graduation canceled, was likely to be associated with a higher increase in anxiety and depression symptoms [11-13].

Data collected from adolescents since the start of the COVID-19 pandemic tend to confirm their significant rates of depression and anxiety symptoms. Indeed, Chinese and Indian studies showed that the prevalence of anxiety symptoms (including post-traumatic stress disorder (PTSD) symptoms) varied between 8 and 37\% during confinement and that of depressive symptoms between 12 and 44\% [3, 14-16]. An Indian study further showed that confined adolescents experience significantly more worries, helplessness, and fear than non-confined adolescents [17].

\section{A Unique Confinement Context for Each Adolescent}

Researchers worldwide highlight the significant heterogeneity in the ways individuals experienced confinement, mainly according to their sex and living conditions during the lockdown. Some studies in Asia suggest that a higher prevalence of psychological distress was present in adolescent girls during the COVID-19 pandemic, compared to normal times [3]. School closures have also contributed to widen social inequalities and increase discrepancies in education and health $[18,19]$. Indeed, by being confined at home, adolescents no longer had the opportunity to evolve within the school environment, which in normal times ensures a relative reduction of these disparities. The adolescents' habits and the support they received during lockdown were also likely to be heterogeneous. For instance, some youths experienced confinement in more comfortable and healthy conditions than others, 
which may have impacted their mental health. Existing studies all support the assertion that confinement is associated with distress in teenagers, but whether or not this association is a matter of adolescents habits during confinement such as their sleep duration, screen time, daily schedule, physical activity, and time devoted to schoolwork, which represent positive development indicators among adolescents, remains unclear [20]. Some adolescents who were less anxious about homeschooling may also have taken advantage of confinement to try new activities, which a can be a source of positive youth development and mental health, while others who generally performed lower, may have felt distressed at being left on their own for their learning. Finally, the support that adolescents received from parents or teachers also varied significantly depending on whether their parents worked outside or not, or depending on the school procedures to contact and support their students. Yet, whether and how these factors were associated with adolescent mental health is unknown. Thus, they ought to be addressed as a way of understanding adolescent psychological distress and well-being during confinement.

The present study thus aims to identify the sociodemographic characteristics (age, family composition, achievement), confinement habits (i.e., schedule, new hobby, sleep duration, cellphone and computer use, sport, schoolwork time), and sources of support (from parents and teachers) associated with anxious (somatic, generalized, traumatic) and depressive symptoms (somatic, affective) in adolescents during confinement. Given the significant gender differences in the prevalence of adolescents' psychological distress, this study will also compare boys' and girls' confinement habits and their associations with symptoms.

\section{Methodology}

\section{Study Design and Participants}

Between April 8 and April 30, 2020, Quebec adolescents aged between 12 and 17 were invited to answer anonymously to an online survey on their well-being during confinement. Initially, the invitation to participate was posted on social media. Next, partners from several schools and social service organizations promoted the study by sending emails to parents. After providing parental consent, participants were invited to complete the questionnaire at the time of their choice. A total of 895 adolescents completed the questionnaire $(M$ age $=14.7, S D=1.7)$. The sample is characterized by a significant disproportion between boys and girls (74\%). The majority of participants were born in Canada (97\%) from parents born in Canada (59\%), and lived with both parents (59\%). With regard to the parents' professional situation, $42 \%$ of adolescents had at least one of their parents who worked outside the home during confinement, and $10 \%$ had two parents who worked outside. More than half of adolescents (57\%) reported being in contact with their teachers, and $26 \%$ reported receiving support from their parents to do their schoolwork.

\section{Measures}

Outcomes Variables A French validated version of the Center for Epidemiologic Studies Depression Scale (CES-D) was used to measure the presence and the severity of depressive symptoms. Three different aspects of depression were assessed: Depressed affect (7 items; e.g., I felt sad) ( $\alpha=0.94)$, Somatic complaints (7 items; e.g., My sleep was restless) 
$(\alpha=0.85)$, and Positive affect (reversed) (4 items; e.g., I enjoyed life) $(\alpha=0.84)$. Adolescents reported the presence of these symptoms from the beginning of confinement using a 6-point Likert scale $(1=$ never, to $6=$ most of the time $)$.

Anxiety symptoms were reported with three scales from the validated French version of The Screen for Child Anxiety Related Disorders-Revised (SCARED-R) [21-23]: Generalized Anxiety Disorder Symptoms (7 items; e.g., I worry about the future) $(\alpha=0.85)$, Significant somatic symptoms (7 items; e.g., When frightened, I feel like throwing up) $(\alpha=0.84)$, and Traumatic stress disorder symptoms (4 items; e.g., I try not to think about a very aversive event I once experienced $(\alpha=0.84)$. Teenagers were asked to rate how frequently they experienced each symptom from the beginning of confinement using a 3-point Likert scale $(0=$ almost never, to $2=$ often $)$.

Independent Variables Sociodemographic variables were self-reported by adolescents: Sex $(0=$ male $; 1=$ female $)$, age $(12$ to 17 years old $)$, family composition $(0=$ nuclear family; $1=$ other $)$, and presence of siblings $(0=$ single kid; $1=\operatorname{sibling}(s))$.

The adolescents' academic achievement was assessed using two items, one relating to language and the other to mathematics (e.g., "thinking about your grades in math, how do you rank compared to other students?") to which participant responded using a five-point Likert scale ( $1=I$ am among the least performing, to 5=I am among the most performing). This type of measurement has been shown in a large-scale study to be just as sensitive as individual performance tests [24].

Questions developed for this study (see Table 1 for details) were used to assess confinement habits (schedule, new hobby, sleeping duration, cell phone and computer use, physical activity, schoolwork) and sources of support (parents and teachers).

\section{Statistical Analyses}

First, descriptive statistics and bivariate correlations were performed between variables. Second, independent sample T-tests were performed to compare boys and girls with respect to their mean differences in symptoms of psychological distress and time spent doing activities, using SPSS 27. We also calculated the independent samples effect sizes to assess the magnitude of the difference in means between the groups using Cohen's $d$ [25]. An effect size of 0.2 is small, 0.5 moderate, and 0.8 large. Third, using Mplus 8.4 and the maximum likelihood estimation with robust standard errors method (MLR), we performed multiple regression to assess the associations between sociodemographic characteristics, confinement habits, support and adolescents' internalized symptoms. Together with Mplus' Full Information Maximum Likelihood, this procedure allowed handling missing data. There were between $0.0 \%$ and $1.7 \%$ of missing values in our sample, which globally corresponds to $0.5 \%$ on all 18 variables. All predictors were entered simultaneously into the model to account for covariance between them. Model fit was assessed using the chi-square statistic $\left(\chi^{2}\right)$, the Root Mean Square Error of Approximation (RMSEA), the Comparative Fit Index (CFI), and the Tucker-Lewis Index (TLI). RMSEA values smaller than 0.08 and 0.06 respectively suggest adequate and excellent model fit. Values above 0.90 and 0.95 for the CFI and TLI respectively indicate adequate and excellent model fit [26, 27]. Fourth, the predictive equivalence of the regression paths was assessed between boys and girls. To do so, we compared the same predictive model with no additional constraints between genders to a second model in which regression slopes were constrained to equality between 


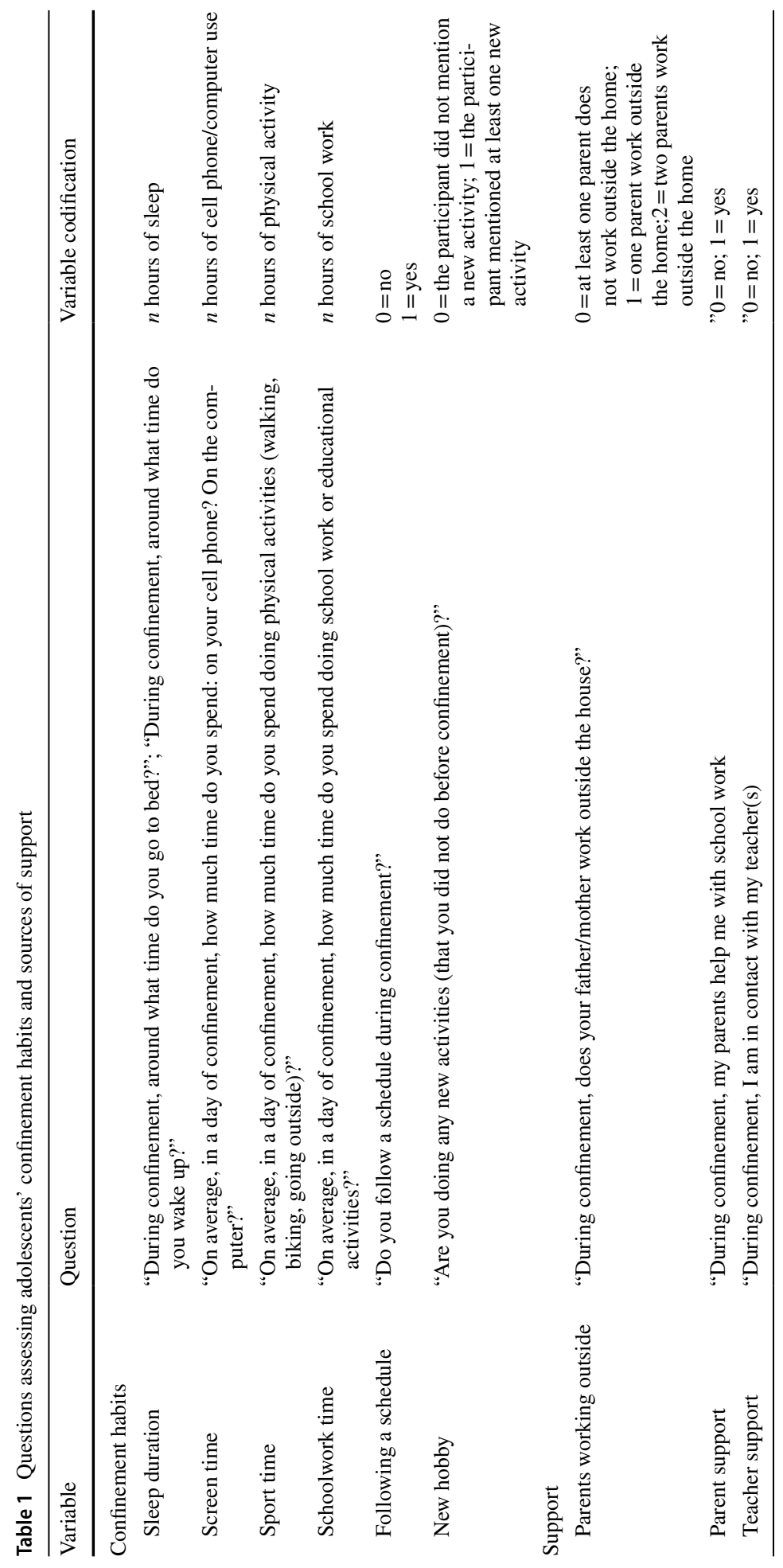


genders. A model is considered invariant if the RMSEA does not increase by more than 0.015 and the CFI and TLI do not decrease by more than 0.010 [28, 29]. A model was considered invariant if the RMSEA did not increase by more than 0.015 , the CFI did not decrease by more than 0.010 and the TLI did not decrease by more than 0.010 .

\section{Results}

No strong correlation was observed between the predictors, indicating a low risk of multicollinearity in the model (Table 2). Descriptive statistics are presented for each group (Table 3). The results of the T-tests (Table 4) indicated that compared to boys, girls reported higher levels of anxiety (somatic, generalized, and traumatic) and depressive symptoms (somatic and affect) during confinement. The magnitude of these differences is moderate. Boys and girls reported similar levels of positive affect. Girls also reported using their cellphones more often, but boys used computers more often, these differences are moderate and small, respectively. Boys and girls did not differ in their sleep duration, schoolwork, and sport habits.

The first path analysis model performed with all parameters allowed to vary between boys and girls presented excellent fit indices $\left(\chi^{2}=0.711(\mathrm{df}=0) ; p<0.000\right.$; RMSEA $=0.000 ; \mathrm{CFI}=0.991 ; \mathrm{TLI}=1.000)$. The second model, which aimed to assess predictive equivalence between genders, had a significant decrease in model fit $\left(\chi^{2}=112.978\right.$ $(\mathrm{df}=105) p=0.280$; RMSEA $=0.013 ; \mathrm{CFI}=0.903$; TLI=0.806). Thus, we tested a third model in which regression paths were progressively freed between genders to identify those that were not invariant. Freeing one path resulted in an excellent fit $\left(\chi^{2}=101.376\right.$ $(\mathrm{df}=104) ; p=0.555$; RMSEA $=0.000 ; \mathrm{CFI}=1.000$; TLI = 1.064). The association between sleep hours and somatic anxiety was found to differ between boys and girls. However, the association was not significant in both groups, although it varied in direction and magnitude (boys: $b=12.028$ (s.e. $=6.424$ ), $p=0.061, \beta=0.192$; girls: $b=-2.895$ (s.e. $=2.369$ ), $p=0.222, \beta=-0.057)$.

Regarding sociodemographic characteristics, being in an intact family was associated with higher levels of traumatic anxiety symptoms (Table 5). All other sociodemographic variables were not significantly associated with anxious and depressive symptoms. In terms of confinement habits, more time spent on the cellphone was associated with lower levels of traumatic anxiety, more time spent playing sports was associated with lower levels of positive affect (reversed), more time spent doing schoolwork was associated with lower levels of somatic depression and depressive affect, and finding a new hobby as associated with lower levels of somatic depression. Having a schedule, sleep duration, and time spent on the computer were not associated with anxiety and depression symptoms. Regarding the support variables, adolescents who have parents working outside the home reported lower levels of depressive affects.

\section{Discussion}

This study's main objective was to describe the associations between variables accounting for the heterogeneity in the adolescents' confinement experience with their anxiety and depression symptoms. A complementary objective of the study was to identify differences between boys and girls. Some sociodemographic characteristics (family status), 


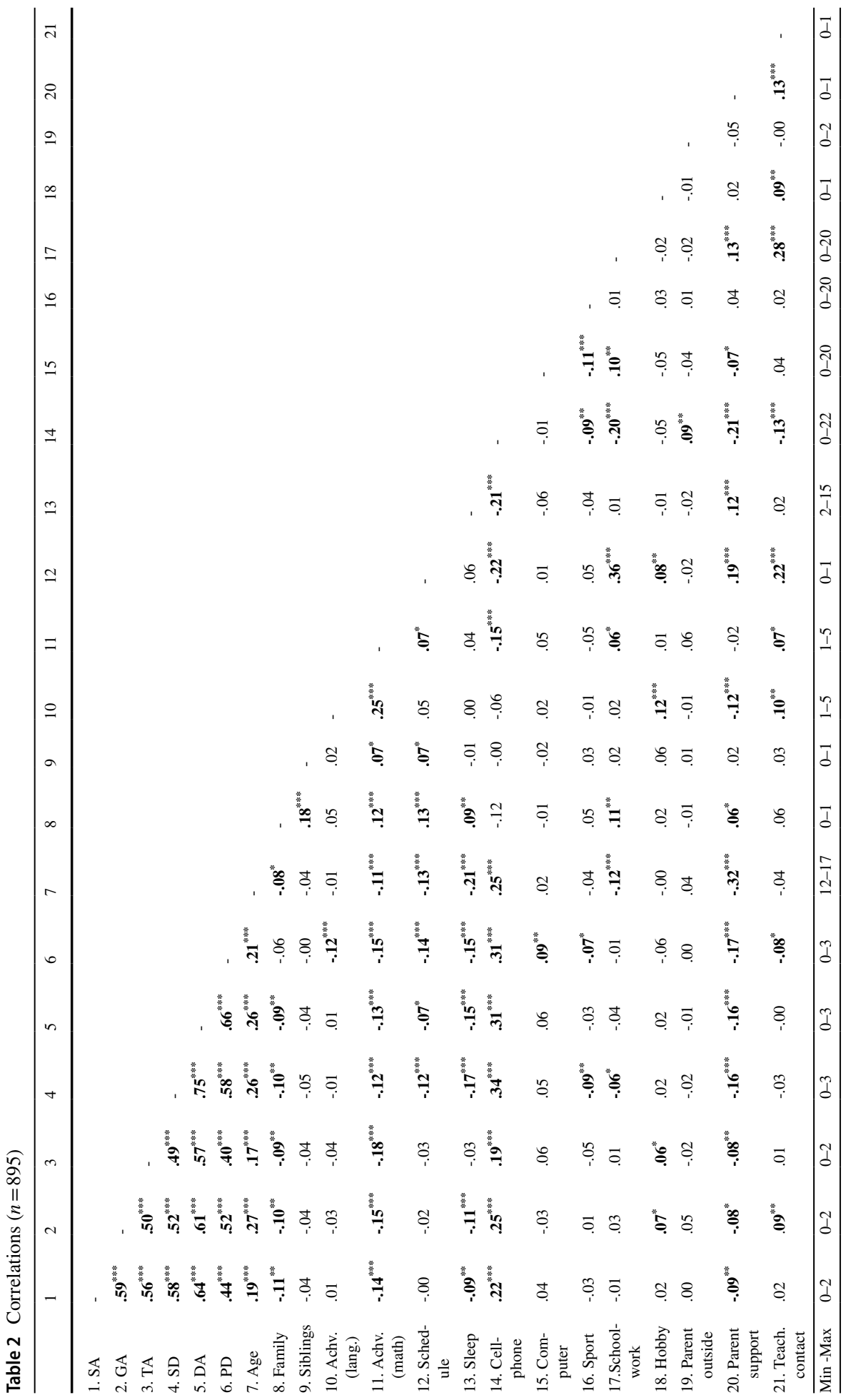




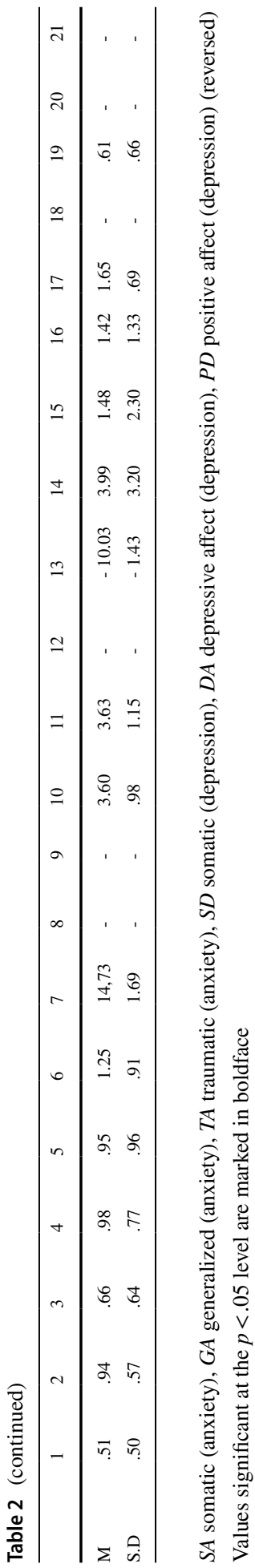

Springer 
Table 3 Descriptive statistics

\begin{tabular}{lll}
\hline & Boys $(n=235)$ & Girls $(n=660)$ \\
\hline $\begin{array}{l}\text { Sociodemographic characteristics } \\
\quad \text { Age (M(S.D.)) }\end{array}$ & $14.4(1.6)$ & $14.8(1.7)$ \\
Family composition & $60 \%$ & $58 \%$ \\
$\quad$ Living with both parents & $81 \%$ & $81 \%$ \\
$\quad$ Having siblings & & \\
Achievement (M(S.D.)) & $3.78(1.14)$ & $3.40(1.03)$ \\
$\quad$ Maths & $3.58(1.14)$ & $3.68(.95)$ \\
Language & & $59 \%$ \\
Confinement habits & $59 \%$ & $76 \%$ \\
$\quad$ Following a schedule during confinement & $62 \%$ & \\
$\quad$ Having a new hobby during confinement & & $48 \%$ \\
Support & & $43 \%$ \\
Parents work situation & $50 \%$ & $9 \%$ \\
Parents at home & $39 \%$ & $23 \%$ \\
Having one parent working outside home & $11 \%$ & $58 \%$ \\
Having two parents working outside home & $34 \%$ & \\
Parents are helping with schoolwork & $52 \%$ & \\
Having contacts with teacher(s) &
\end{tabular}

confinement habits (new hobby, using cellphones, doing sports, and time spent doing schoolwork), and support variables (parents working outside the home) were significantly associated with anxiety and/or depressive symptoms. However, although girls reported significantly higher levels of anxiety and depressive symptoms in confinement than boys did, as in normal time when there is no pandemic [30,31], the associations between the predictors and the symptoms remained the same for boys and girls.

\section{Sociodemographic Characteristics and Internalized Symptoms}

Youth who lived with both of their parents reported higher levels of traumatic anxiety. This result is surprising as the financial stability resulting from living with both parents could have helped alleviate stress in this time of economic instability for many families [32]. However, a study conducted among American adults shows that they have experienced conflict escalations in their romantic partnerships during confinement [33]. Therefore, this surprising association could be explained by the fact that youth living with two parents may have been more exposed to marital conflict, a significant stressor for adolescents that can generates anxiety [34]. Further studies will be needed to understand better the impact of family dynamics on adolescents' mental health in confinement. 
Table 4 Means, standard deviations, and independent sample comparisons for boys and girls)

\begin{tabular}{|c|c|c|c|c|c|c|c|c|}
\hline & \multicolumn{2}{|c|}{$\begin{array}{l}\text { Boys }(B) \\
(n=235)\end{array}$} & \multicolumn{2}{|c|}{$\begin{array}{l}\text { Girls }(G) \\
(n=660)\end{array}$} & \multicolumn{4}{|c|}{ Independent samples t-test } \\
\hline & $M$ & $S . D$ & $M$ & S.D & $t$ & $p$ & $\begin{array}{l}\text { Group } \\
\text { compari- } \\
\text { sons }\end{array}$ & Cohen's d \\
\hline \multicolumn{9}{|l|}{ Internalized symptoms } \\
\hline Somatic anxiety & .248 & .344 & .600 & .508 & 12.818 & .000 & $\mathbf{B}<\mathbf{G}$ & .750 \\
\hline Generalized anxiety & .626 & .489 & 1.059 & .555 & 12.247 & .001 & $\mathbf{B}<\mathbf{G}$ & .804 \\
\hline Traumatic anxiety & .382 & .496 & .742 & .651 & 9.552 & .000 & $\mathbf{B}<\mathbf{G}$ & .587 \\
\hline Somatic depression & .636 & .664 & 1.086 & .766 & 9.327 & .002 & $\mathbf{B}<\mathbf{G}$ & .608 \\
\hline Depressive affect & .423 & .678 & 1.120 & .974 & 13.036 & .000 & $\mathbf{B}<\mathbf{G}$ & .771 \\
\hline Positive affect $(r)$ & .942 & .869 & 1.35 & .897 & 6.707 & .085 & $n . s$ & .460 \\
\hline \multicolumn{9}{|l|}{ Confinement habits } \\
\hline Sleep duration & 10.029 & 1.536 & 10.026 & 1.391 & -.027 & .133 & $n . s$ & -.002 \\
\hline Cellphone & 2.699 & 2.706 & 4.464 & 3.241 & 8.846 & .000 & $\mathbf{B}<\mathbf{G}$ & .568 \\
\hline Computer & 1.655 & 2.473 & 1.420 & 2.233 & -1.400 & .006 & $\mathbf{B}>\mathbf{G}$ & -.102 \\
\hline Schoolwork & 1.601 & 1.797 & 1.669 & 1.652 & .582 & .890 & $n . s$ & .041 \\
\hline Sport & 1.427 & 1.238 & 1.417 & 1.361 & -.098 & .278 & $n . s$ & -.007 \\
\hline
\end{tabular}

\section{Adolescents' Habits During Confinement and Internalized Symptoms}

Time spent using their cellphone was associated with a lower level of psychological distress symptoms in adolescents. Specifically, there was a lower prevalence of intrusive thoughts about a negative event. Again, this result is surprising because some studies showed that those who report more considerable daily screen time during lockdown experienced poorer well-being [14]. Adolescents often use their cellphones to consult social media. Yet, high exposure to social media has been particularly singled out because it increases sensitivity to social comparison and peer judgment and could directly contribute to the onset or worsening of anxiety and depressive symptoms $[35,36]$. Nevertheless, social media are very useful amid physical distancing to maintain a social connection, access information and resources related to COVID-19, allow teenagers to continue developing their identity by providing a territory of autonomous exploration outside adult supervision, and seek help for those who find themselves in an unsafe family environment. Girls also reported their cellphone usage as being significantly higher during confinement (on average $4.5 \mathrm{~h}$ ) compared to boys (on average $2.7 \mathrm{~h}$ ) and the effect size of this difference was medium. The fact that girls in confinement used their cellphones more than boys did possibly reflects their higher propensity to favor social support as a coping strategy. It is crucial to keep in mind that during the lockdown, the cellphone was the only way for teenagers to reach their friends who are their primary source of social support $[9,10]$. It would be essential to focus on adolescents' behaviors online, that is, how they use their cellphone and with whom they interact, in order to have a better understanding of this complex variable.

Teenagers who spent more time exercising reported more positive affects, like feeling happy, valued, and confident about the future, which is not surprising given the similar results from studies on adult and adolescents populations in confinement [37, 37]. Teenagers who experienced depression symptoms were perhaps less likely to engage in physical 


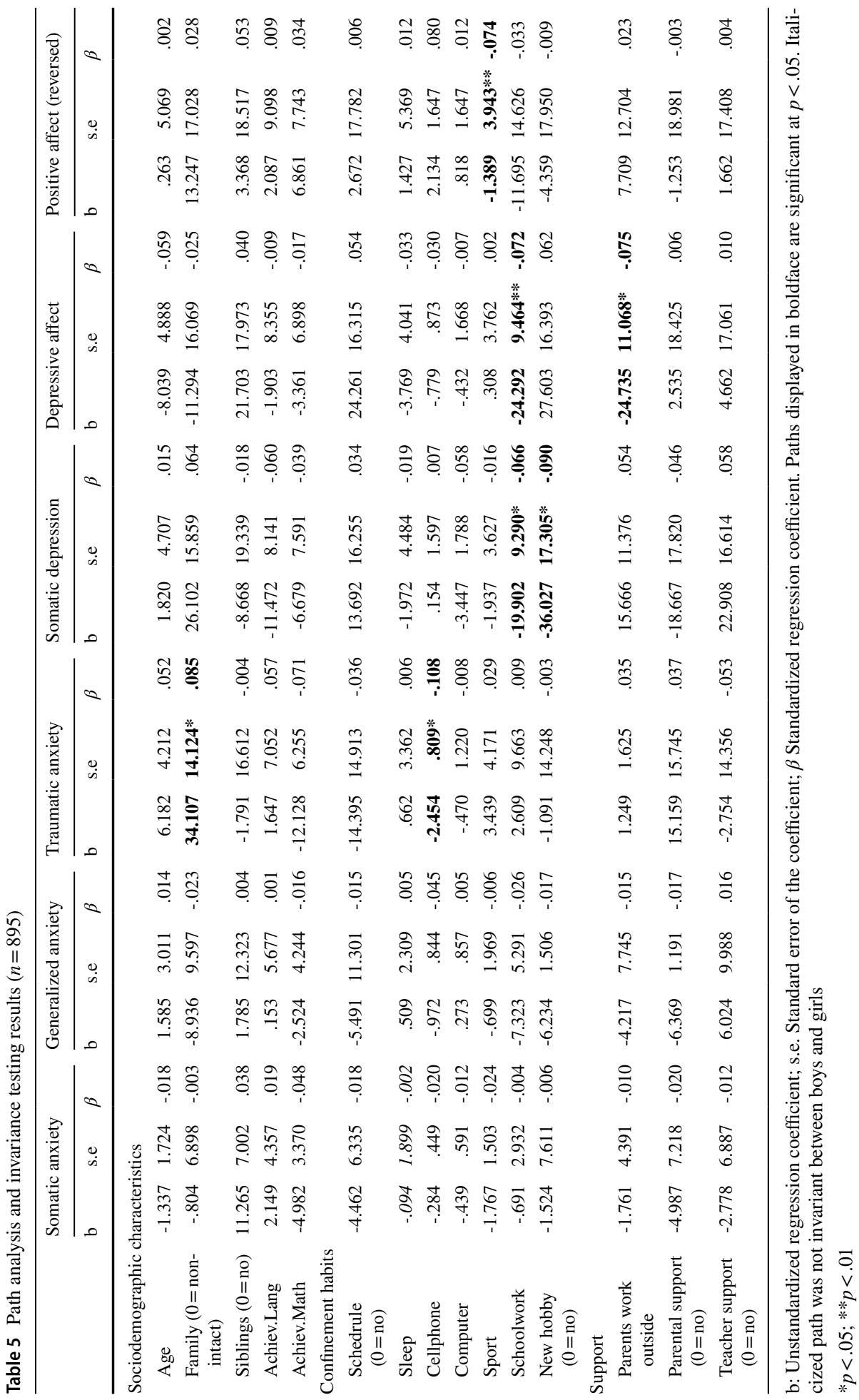


activity because they lacked energy [38]. It is, therefore, essential to pay attention to sports as a protective factor for mental health in the context adolescence and confinement, two conditions that tend to increase sedentary lifestyle [39, 40]. Adolescents who spent more time doing schoolwork reported less difficulty sleeping, concentrating, appetite changes, and were feeling less depressed, lonely, or worthless. These results are similar to those of a Canadian study on teenagers. It is possible that maintaining a commitment to school despite the school closure, gave a certain normalcy in the daily life of these adolescents and occupied their minds constructively, thus avoiding boredom and ruminations. Moreover, adolescents who adopted a new hobby while in confinement experienced fewer somatic depressive symptoms such as lack of appetite, liveliness, difficulty sleeping, or concentrating. This result is congruent with the conclusions of a review of various studies conducted with children and adolescents which suggests that taking up creative activities help to manage mental health [41]. Trying a new hobby could be a coping strategy that the teenagers would have deployed to alleviate their stress and strengthen their self-esteem by developing new skills during the lockdown [42]. It is also possible that adolescents who experienced elevated somatic symptoms were simply not mentally and physically available to take an interest in new activities, although the period of confinement was an opportunity to do so given the increase in free time they suddenly had [43].

\section{Support and Internalized Symptoms}

Surprisingly, teenagers whose parents worked outside the home reported less depressive affect, thus feeling less sad and depressed. However, one might think that teenagers whose two parents work outside would had more difficulty in confinement since they may have been left without supervision and support. It is therefore conceivable the fact that parents worked out of home, as they did in normal times, contributed to the feeling of normalcy in the situation, may have limited family conflicts, and financial strains [44].

Several sociodemographic characteristics were not associated with any symptoms of anxiety or depression. This is the case for age, which is somewhat surprising as some studies have shown that being older represents a risk factor for adolescents' psychological distress, in confinement as in normal times particularly as it relates to depressive symptoms [14]. It is possible that, because the model we tested in the present study considered the relative contribution of all other predictors, which was not the case in other studies, it highlighted the predominance of the variables that have turned out to be associated with symptoms.

\section{Strengths and Limitations}

This study, among the first to examine the variables associated with the mental health of adolescents in confinement, has several strengths. It is based on a sample of considerable size and documents a critical moment in the pandemic events. The fact that the analyzes were carried out according to the subtypes of anxiety and depressive symptoms provides more specific avenues for the intervention. The analyzes used to assess the differences between boys and girls were highly rigorous. However, this study has certain limitations. First, it was based on a cross-sectional design, which prohibits any conclusion of causal relationships. Another consequence resulting from this design is that pre-existing mental health diagnoses were not monitored, which would have been relevant since some studies have identified it is an aggravating factor of psychological distress in confinement. Also, 
public health guidelines made it impossible to apply a sampling method at this time. The possibility of selection bias within our sample should be considered given that we relied on voluntary recruitment and solicited a portion of the sample through social media and email. To better understand the significance of the results, it would have been desirable to consider families' socio-economical status, especially in the context of the pandemic where inequalities are increased. Still, it is unfortunately difficult to do so from data reported by adolescents. Finally, it is legitimate to question the accuracy of the self-reported data that accounts for the time spent on daily activities since it can be difficult for adolescents to estimate the amount of time spent doing an activity. Also, the teacher and parent support variables were very limited. Ideally, the support would have directly, qualitatively, and more precisely measured.

\section{Conclusion}

This study provided a portrait of the characteristics and habits of adolescents in confinement associated with their symptoms of anxiety and depression. Adolescents who spent more time doing schoolwork, sports, and used their cellphones, had fewer symptoms during confinement. This is also the case for those who discovered a new hobby and whose parents were working outside the home. How sociodemographic characteristics, confinement habits, and support were associated with symptoms was similar for boys and girls. Yet, to disentangle the direction of these associations, it becomes essential for future studies to rely on longitudinal designs and populational data. However, this study allows researchers and clinicians to better understand how adolescents experience confinement. In the eventuality of re-confinement, this study will help guide actions to support boys' and girls' mental health and provide concrete avenues for intervention.

Abbreviations COVID-19: Coronavirus Disease 2019; CES-D: Center for Epidemiologic Studies Depression Scale; CFI: Comparative Fit Index; DA: Depressive affect; GA: Generalized anxiety; MLR: Robust standard errors method; PD: Positive affect (depression); PTSD: Post traumatic stress disorder; RMSEA: Root Mean Square Error of Approximation; SA: Somatic anxiety; SCARED-R: The Screen for Child Anxiety Related Disorders-Revised; SD: Somatic (depression); SPSS: Statistical Package for Social Science; TA: Traumatic anxiety; TLI: Tucker-Lewis Index

Author Contributions First author analyzed and interpreted the data and leaded the redaction of the article.

Second author contributed to the study design and redaction of the article.

Third contributed to the study design and redaction of the article.

Fourth contributed to the redaction of the article.

Fifth analyzed and interpreted the data and contributed to the redaction of the article.

All authors read and approved the final manuscript.

The first draft of the manuscript was written by First author and all authors commented on previous versions of the manuscript. All authors read and approved the final manuscript.

Data Availability The datasets used and/or analysed during the current study are available from the corresponding author on reasonable request. 


\section{Declarations}

Ethics Approval and Consent to Participate This study was approved by the Research Ethical Committee of Université du Québec en Outaouais (UQO). All the participants provided a written parental consent.

Consent for Publication Consent for publication was included in the parental consent form..

Conflict of Interest The authors declare that they have no conflict of interest.

\section{References}

1. Lee J. Features mental health effects of school closures during COVID-19. Lancet Child Adolesc Health. 2020;4(6):421. https://doi.org/10.1016/S2352-4642(20)30109-7.

2. Power E, Hughes S, Cotter D, Cannon M. Youth mental health in the time of COVID-19. Ir J Psychol Med. 2020;1-15. https://doi.org/10.1017/ipm.2020.84.

3. Zhou S-J, Zhang L-G, Wang L-L, Guo Z-C, Wang J-Q, Chen J-C, et al. Prevalence and sociodemographic correlates of psychological health problems in Chinese adolescents during the outbreak of COVID-19. Eur Child Adolesc Psychiatry. 2020;29(6):749-58. https://doi.org/10.1007/ s00787-020-01541-4.

4. Costello EJ, Copeland W, Angold A. Trends in psychopathology across the adolescent years: what changes when children become adolescents, and when adolescents become adults? J Child Psychol Psychiatry. 2011;52(10):1015-25. https://doi.org/10.1111/j.1469-7610.2011.02446.x.

5. Hammen C. Adolescent depression: stressful interpersonal contexts and risk for recurrence. Curr Dir PsycholSci. 2009;18(4):200-4. https://doi.org/10.1111/j.1467-8721.2009.01636.x.

6. Orben A, Tomova L, Blackmore S-J. The effects of social deprivation on adolescent social development and mental health. Lancet Child Adolesc Health. 2020;4(8):634-40. https://doi.org/10.1016/ S2352-4642(20)30186-3.

7. Dahl RE, Allen NB, Wilbrecht L, Suleiman AB. Importance of investing in adolescence from a developmental science perspective. Nature. 2018;554(7693):441-50. https://doi.org/10.1038/natur e25770.

8. Steinberg L. Adolescence. 11th ed. New York: McGraw-Hill Education; 2017.

9. Center for Disease Control and Prevention (CDC). Coronavirus disease (COVID-19). Atlanta: Center for Disease Control and Prevention (CDC); 2019. Accessed 25 Jul 2020. Available from: https://www. cdc.gov/coronavirus/2019-ncov/daily-life-coping/managing-stress-anxiety.html.

10. Fegert JM, Vitiello B, Plener PL, Clemens V. Challenges and burden of the Coronavirus 2019 (COVID-19) pandemic for child and adolescent mental health: a narrative review to highlight clinical and research needs in the acute phase and the long return to normality. Child Adolesc Psychiatry Ment Health. 2020;14(1):20. https://doi.org/10.1186/s13034-020-00329-3.

11. Golberstein E, Wen H, Miller BF. Coronavirus disease 2019 (COVID-19) and mental health for children and adolescents. JAMA Pediatr. 2020;174(9):819. https://doi.org/10.1001/jamapediat rics.2020.1456.

12. Healthy children.org. Teens \& COVID-19: challenges and opportunities during the outbreak. Itasca: American Academy of Pediatrics; 2020. Accessed 1 Apr 2020. Available from: https://www.healthychi ldren.org/English/health-issues/conditions/chest-lungs/Pages/Teens-and-COVID-19.aspx.

13. Loades ME, Chatburn E, Higson-Sweeney N, Reynolds S, Shafran R, Brigden A, et al. Rapid systematic review: the impact of social isolation and loneliness on the mental health of children and adolescents in the context of COVID-19. J Am Acad Child Adolesc Psychiatry. 2020;59(11):1218-39. https ://doi.org/10.1016/j.jaac.2020.05.009.

14. Chen F, Zheng D, Liu J, Gong Y, Guan Z, Lou D. Depression and anxiety among adolescents during COVID-19: a cross-sectional study. Brain BehavImmun. 2020;88:36-8. https://doi.org/10.1016/j. bbi.2020.05.061.

15. Liang L, Ren H, Cao R, Hu Y, Qin Z, Li C, et al. The effect of COVID-19 on youth mental health. Psychiatr Q. 2020;91(3):841-52. https://doi.org/10.1007/s11126-020-09744-3.

16. Qu M, Yang K, Cao Y, Si T, Wang X, Xiu MH, et al. Mental health status of adolescents after family confinement during the COVID-19 outbreak. Lancet. 2020. https://doi.org/10.2139/ssrn.3594586. 
17. Saurabh K, Ranjan S. Compliance and psychosocial impact of quarantine in children and adolescents due to COVID-19 pandemic. Indian J Pediatr. 2020;1. https://doi.org/10.1007/s12098-020-03347-3

18. Armitage R, Nellums LB. Considering inequalities in the school closure response to COVID-19. Lancet Glob Health. 2020;8(5):e644. https://doi.org/10.1016/S2214-109X(20)30116-9.

19. Van Lancker W, Parolin Z. COVID-19, school closures, and child poverty: a social crisis in the making. Lancet Public Health. 2020;5(5):e243-4. https://doi.org/10.1016/S2468-2667(20)30084-0.

20. Rutledge K. Anticipating the mental health effects of COVID-19 in youth: social isolation in a digital age. J Am Acad Child Adolesc Psychiatry. 2020;7:8-11. Available from: https://els-jbsprod-cdn.jbs.elsevierhealth.com/pb/assets/raw/Health\%20Advance/journals/jaac/connect7_2. pdf\#page=8. Accessed Nov 2020.

21. Birmaher B, Brent DA, Chiappetta L, Bridge J, Monga S, Baugher M. Psychometric properties of the Screen for Child Anxiety Related Emotional Disorders (SCARED): a replication study. J Am Acad Child Adolesc Psychiatry. 1999;38(10):1230-6. https://doi.org/10.1097/00004583-199910000-00011.

22. Martin A, Gosselin P. Psychometric properties of the French adaptation of a measure for symptoms of anxiety disorders among children and adolescents (SCARED-R). Can J BehavSci. 2012;44(1):70-6. https://doi.org/10.1037/a0023103.

23. Muris P, Merckelbach H, Van Brakel A, Mayer AB. The revised version of the screen for child anxiety related emotional disorders (SCARED-R): further evidence for its reliability and validity. Anxiety Stress Coping. 1999;12(4):411-25. https://doi.org/10.1080/10615809908249319.

24. Duncan GJ, Dowsett CJ, Claessens A, Magnuson K, Huston A, Klebanov P, et al. School readiness and later achievement. Dev Psychol. 2007;43(6):1428-46. https://doi.org/10.1037/0012-1649.43.6.1428.

25. Cohen J. Statistical power analysis for the behavioral sciences. 2nd ed. New Jersey: Lawrence Erlbaum Associates Publishers; 1988.

26. Chen FF. Sensitivity of goodness of fit indexes to lack of measurement invariance. StructEqu Model. 2007;14(3):464-504. https://doi.org/10.1080/10705510701301834.

27. Cheung GW, Rensvold RB. Evaluating goodness-of-fit indexes for testing measurement invariance. StructEqu Model. 2002;9(2):233-55. https://doi.org/10.1207/S15328007SEM0902_5.

28. Hu LT, Bentler PM. Cutoff criteria for fit indexes in covariance structure analysis: conventional criteria versus new alternatives. StructEqu Modeling. 1999;6(1):1-55. https://doi.org/10.1080/10705 519909540118.

29. Marsh HW, Hau K, Grayson D. Goodness of fit in structural equationmodels. In: Maydeu-Olivares A, McArdle JJ, editors. Contemporarypsychometrics: afestschrift for Roderick P. McDonald. New Jersey: Erlbaum; 2005. p. 275-340.

30. Ge X, Conger RD, Elder GH Jr. Pubertal transition, stressful life events, and the emergence of gender differences in adolescent depressive symptoms. Dev Psychol. 2001;37(3):404-17. https://doi. org/10.1037//0012-1649.37.3.404.

31. Ohannessian CM, Cavanaugh A, Cheeseman K. Gender and racial/ethnic differences in anxiety disorders during adolescence. Adolesc Psychiatry. 2017;7(1). https://doi.org/10.2174/2210676607 666170908160057

32. Martin A, Markhvida M, Hallegatte S, Walsh B. Socio-economic impacts of COVID-19 on household consumption and poverty. Econ Disaster Clim Chang. 2020;1-27. https://doi.org/10.1007/ s41885-020-00070-3

33. Luetke M, Hensel D, Herbenick D, Rosenberg M. Romantic relationship conflict due to the COVID19 pandemic and changes in intimate and sexual behaviors in a nationally representative sample of American adults. J Sex Marital Ther. 2020;1-16. https://doi.org/10.1080/0092623X.2020.1810185

34. Spence SH, Najman JM, Bor W, O’Callaghan MJ, Williams GM. Maternal anxiety and depression, poverty and marital relationship factors during early childhood as predictors of anxiety and depressive symptoms in adolescence. J Child Psychol Psychiatry. 2002;43(4):457-69. https://doi. org/10.1111/1469-7610.00037.

35. Gao J, Zheng P, Jia Y, Chen H, Mao Y, Chen S, et al. Mental health problems and social media exposure during COVID-19 outbreak. PLoS ONE. 2020;15(4):e0231924. https://doi.org/10.1371/ journal.pone.0231924.

36. Twenge JM, Joiner TE, Rogers ML, Martin GN. Increases in depressive symptoms, suicide-related outcomes, and suicide rates among US adolescents after 2010 and links to increased new media screen time. ClinPsycholSci. 2018;6(1):3-17. https://doi.org/10.1177/2167702617723376.

37. Khan AH, Sultana MS, Hossain S, Hasan MT, Ahmed HU, Sikder MT. The impact of COVID-19 pandemic on mental health and wellbeing among home quarantined Bangladeshi students: a crosssectional pilot study. J Affect Disord. 2020. https://doi.org/10.1016/j.jad.2020.07.135.

38. McHale SM, Crouter AC, Tucker CJ. Free-time activities in middle childhood: links with adjustment in early adolescence. Child Dev. 2001;72(6):1764-78. https://doi.org/10.1111/1467-8624.00377. 
39. Guthold R, Stevens GA, Riley LM, Bull FC. Worldwide trends in insufficient physical activity from 2001 to 2016: a pooled analysis of 358 population-based surveys with 1.9 million participants. Lancet Glob Health. 2018;6(10):e1077-86. https://doi.org/10.1016/S2214-109X(18)30357-7.

40. Papaioannou AG, Schinke RJ, Chang YK, Kim YH, Duda JL. Physical activity, health and wellbeing in an imposed social distanced world. Int J Sport ExercPsychol. 2020;18(4):414-9. https:// doi.org/10.1080/1612197X.2020.1773195.

41. Singh S, Roy D, Sinha K, Parveen S, Sharma G, Joshi G. Impact of COVID-19 and lockdown on mental health of children and adolescents: a narrative review with recommendations. Psychiatry Res. 2020;293(113429):113429. https://doi.org/10.1016/j.psychres.2020.113429.

42. Lam CB, McHale SM. Time use as cause and consequence of youth development. Child Dev Perspect. 2015;9(1):20-5. https://doi.org/10.1111/cdep.12100.

43. Desha LN, Ziviani JM. Use of time in childhood and adolescence: a literature review on the nature of activity participation and depression. AustOccupTher J. 2007;54(1):4-10. https://doi.org/10.111 1/j.1440-1630.2006.00649.x.

44. Imran N, Zeshan M, Pervaiz Z. Mental healthconsiderations for children and adolescents in COVID-19 pandemic. Pak J Med Sci. 2020;36((COVID-S4)):S67-72. https://doi.org/10.12669/pjms.36.COVID 19-S4.2759.

Publisher's Note Springer Nature remains neutral with regard to jurisdictional claims in published maps and institutional affiliations.

Kristel Tardif-Grenier, Ph.D. is a Professor at Université du Québec en Outaouais (Canada). Her main research interests are the well-being, coping strategies, and social support in adolescents and emerging adults with an immigrant background.

Isabelle Archambault, Ph.D. is a Professor at Université de Montréal and holds the Canada Research Chair on school, child well-being, and educational success. Anchored in a social justice perspective, her work focuses on the development of best practices supporting different populations of children.

Véronique Dupéré, Ph.D. is a Professor at Université de Montréal and holds the Canada Research Chair on the Transition to Adulthood. Her research focuses on adolescents and young adults and is framed in a life course trajectories approach.

Amy K. Marks, Ph.D. is a Professor and Chair at the Department of Psychology of Suffolk University. She is interested in positive development and how cultural and social contexts like immigration influence youth development.

Elizabeth Olivier, Ph.D. is a Postdoctoral fellow in the department of Psychology at Concordia University. Her research focuses on student mental health and psychosocial adjustment and its impact on school motivation, engagement, and success.

\section{Authors and Affiliations}

\section{Kristel Tardif-Grenier ${ }^{1}$ (D) Isabelle Archambault ${ }^{2} \cdot$ Véronique Dupéré $^{2}$. Amy K. Marks ${ }^{3}$ - Elizabeth Olivier ${ }^{4}$}

Isabelle Archambault

isabelle.archambault@umontreal.ca

Véronique Dupéré

veronique.dupere@umontreal.ca

Amy K. Marks

akmarks@suffolk.edu

Elizabeth Olivier

elizabeth.abby.olivier@gmail.com 
1 Department of Psychoeducation and Psychology, Université du Québec en Outaouais, 5, Saint-Joseph street, Saint-Jerome, QC J7Z 0B7, Canada

2 School of Psychoeducation, Université de Montréal, 90 Vincent d'Indy street, Montréal, Québec H2V 2S9, Canada

3 Suffolk University, 73 Tremont St, Boston, MA 02108, USA

4 Concordia University, 1455 De Maisonneuve Blvd. W, Montreal, QC H3G 1M8, Canada 